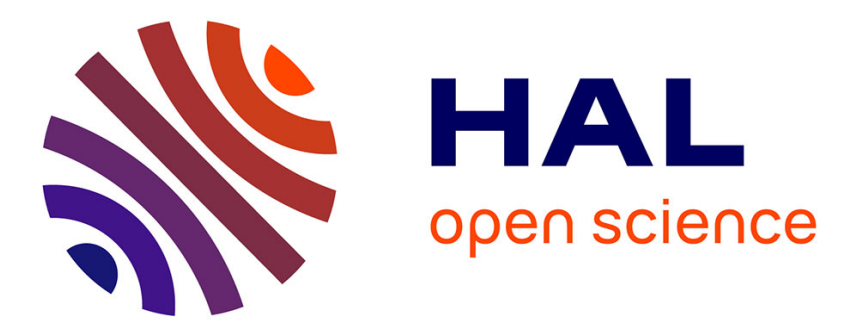

\title{
Towards Urban Fabrics Characterization Based on Buildings Footprints
}

\author{
Rachid Hamaina, Thomas Leduc, Guillaume Moreau
}

\section{To cite this version:}

Rachid Hamaina, Thomas Leduc, Guillaume Moreau. Towards Urban Fabrics Characterization Based on Buildings Footprints. Jérôme Gensel; Didier Josselin; Danny Vandenbroucke. Bridging the Geographic Information Sciences - International AGILE'2012 Conference, Avignon (France), April, 24-27, 2012, Springer Berlin Heidelberg, pp.327-346, 2012, 978-3-642-29062-6. 10.1007/978-3-642-290633_18. hal-01347299

\section{HAL Id: hal-01347299 \\ https://hal.science/hal-01347299}

Submitted on 20 Jul 2016

HAL is a multi-disciplinary open access archive for the deposit and dissemination of scientific research documents, whether they are published or not. The documents may come from teaching and research institutions in France or abroad, or from public or private research centers.
L'archive ouverte pluridisciplinaire HAL, est destinée au dépôt et à la diffusion de documents scientifiques de niveau recherche, publiés ou non, émanant des établissements d'enseignement et de recherche français ou étrangers, des laboratoires publics ou privés. 


\title{
Towards urban fabrics characterization based on buildings footprints
}

Rachid Hamaina, Thomas Leduc, Guillaume Moreau

Lunam Université,

Ecole Centrale de Nantes,

CERMA: Centre d'Etudes et Recherche Méthodologique en Architecture, 6 quai François Mitterrand, BP16202 - 44262 Nantes Cedex 2

\begin{abstract}
Urban fabric characterization is very useful in urban design, planning, modeling and simulation. It is traditionally considered as a descriptive task mainly based on visual inspection of urban plans. Cartographic databases and geographic information systems (GIS) capabilities make possible the analytical formalization of this issue. This paper proposes a renewed approach to characterize urban fabrics using buildings' footprints data. This characterization method handles both architectural form and urban open space morphology since urban space can be intuitively and simply divided into built-up areas (buildings) and non-built-up areas (open spaces). First, we propose to build a mesh of the open space (a morphologic tessellation) and then we formalize relevant urban morphology properties and translate them into a set of indicators (using some common-used indispensable indicators and proposing a new formulation or generalization of a few others). This first step produces a highly dimensional data set for each footprint characterizing both the building and its surrounding open space. This data set is then reduced and classified using a spatial clustering process, the self-organizing maps in this case. Our method only requires buildings' footprints as input data. It can be applied on huge datasets and is independent from urban contexts. The results show that the classification produced is more faithful to ground truth (highlighting the variety of urban morphologic structures) than traditional descriptive characterizations generally lacking open space properties.
\end{abstract}




\section{Introduction}

Urban analysis can contribute to draw a response to the growing environmental issues in urban context. It gives the basis to understand urban dynamics and consequently to inform urban design and planning. There is a close relationship between urban form (configurational characteristics) and urban functions. Urban form characterization as part of urban analysis is very useful for urban modeling and simulation: growth, micro-climate conditions, pollution, noise, mobility, etc. This characterization can be achieved at multiple scales according to the given level of detail: regional (macro-scale) studies, urban (meso-scale) and intra-urban (micro-scale). The intra-urban level is a specific scale because it deals with architectural concerns: buildings and neighborhood (urban public space) morphology.

Formerly, this intra-urban fabric characterization has been described with adjective words (inner city areas, traditional urban fabrics, modern high rise urban fabrics, mid-rise urban fabrics, modern low-rise urban fabrics, suburban areas, etc.). Nowadays, the availability of cartographic databases and GIS enables digital change monitoring and analysis of urban fabric characteristics thus replacing visual inspection and interpretation of city plans and maps.

Some quantitative urban form studies coming from urban geography research have focused on urban fabric characterization. These characterizations often use morphometric indicators (mostly density measures). Even if density has long been used in urban development regulation, it is conceded that it is insufficient to neither characterize nor control urban form production. [Berghauser Pont et al., 2007] suggested an alternative approach to density and used four variables expressing intensity (FSI: Floor Space Index), compactness (GSI: Ground Space Index), pressure on non-built space (OSR: Open Space Ratio) and building height (L: Layers). Unfortunately, these alternatives are still lacking the consideration of neighborhood and urban open space characteristics. Another alternative to density to characterize the urban form patterns is based on the use of fractals. [Thomas et al., 2007] used the fractal dimension of built-up areas to characterize urban fabrics and concluded that this measure considers both morphology and internal structure while density gives just a rough idea of the occupation of the surface. However, this fractal measure considers neither the buildings 3D templates nor the neighboring open space morphology. Another similar type of quantitative studies aiming at characterizing urban patterns (mainly buildings groups and urban blocks) belongs to cartographic generalization research. This type of analysis is based on spatial vector data analysis. The general purpose of these studies is an urban vector data classification to as- 
sociate each buildings group class to a corresponding suitable generalization process. [Boffet and Serra, 2001] used few of the several criteria coming from Gestalt theory (proximity, similarity, good continuation) to identify particular spatial configurations of buildings within urban blocks. In a relatively similar work, [Puissant and al., 2010] perform an urban blocks classification using several descriptive indicators: number of buildings, total built area, density, buildings size and shape. The cartographic generalization purpose makes that no morphologic issues are introduced.

Another way to study the urban spatial structure comes from the architectural field, this is the space syntax theory developed by [Hillier, 1987]. Contrarily to the previous atomist conception of the urban fabrics based on tangible spatial objects (buildings), this is a plenum approach [Couclelis, 1992]. The idea behind the study of the urban open space is that the complex human perception of space (and spatial behavior) may be related to some physical properties of the environment. However, the urban open space is continuous (not cellular like the architectural one), so, its analysis is even more complex. To deal with that, the open space is represented by an axial map (the set of longest lines of view through open space). In space syntax research, the open space is considered as a support of human mobility ignoring thus its architectural and morphologic concerns (supplying air, light, urban squares, etc.).

In the first part of this paper, the objectives of the work are presented. In the second one the methodology is developed, it starts with data preprocessing, then various spatial objects are produced and used in the morphological properties formalization. This methodological part finishes with a spatial clustering process on buildings data. We discuss the results in the third part and we draw some conclusions in the last one.

\section{Objectives}

In a very simple representation, the urban space is composed of the built space (buildings) and the non-built open space (buildings dual space), which corresponds to the aggregation of void in between the surrounding buildings as they get placed and spatially aggregated in the urban space. The spatial relationships between the buildings and these open spaces are essential for the definition of urban environments themselves. So, we believe that a complete characterization of the urban fabrics morphology should take into account not only the intrinsic buildings properties (architectural form) as done traditionally but also their spatial layout in the whole of the urban fabrics. The urban morphology can therefore be sum- 
marized to the characterization of the buildings geometry and the way they spatially aggregate. This double assumption might be translated as a composite analysis based on the one hand, on the buildings templates, and, on the other hand, on their neighboring open spaces. The objective of this work is to translate into a systematic and an analytical method (based on classical vector spatial data) a set of urban fabrics portions mostly defined by adjective words such as inner city areas, traditional urban fabrics, modern high rise urban fabrics, mid-rise urban fabrics, modern lower-rise urban fabrics, suburban areas, etc. This will be achieved by a systematic spatial analysis of both the urban building's footprints and their open spaces surroundings so as to provide a generic method to characterize the urban fabrics morphology. This formalization of several typo-morphology concepts uses exclusively buildings footprints data excluding the use of other input data such as plots, urban blocks or street network. Furthermore, the open space is considered, by extension, an artificial developed streets network providing air, light and even a support for persons' mobility.

\section{Methods}

The characterization of individual buildings of an urban fabric is not sufficient to characterize the whole of the urban fabric itself. We propose to complete traditional urban fabric characterization by using the urban open space morphological characteristics. To achieve this, we should associate buildings footprints data to an open space's geometry. This will allow formalizing individual geometric properties with respect to these two objects and as well as morphological properties requiring the combination of both. Figure 1 summarizes the whole methodology pursued in this paper. First, a spatial data matching process is required to get individual buildings footprints with heights. Second, an open space geometry is proposed to associate every footprint with its neighboring open space. Third, these two spatial objects are used to formalize relevant urban morphology properties into a set of indicators. Finally, we classify the whole study area into homogeneous morphologic sub-areas based on the characteristics of their buildings footprints and on the characteristics of their associated open spaces. The only input data used are buildings footprints. These spatial data are derived from the cadastral plan (Plan Cadastral Informatisé, PCI) and the topographic database provided by the French geographic institute (the so called BD TOPO ${ }^{\circledR}$ ). The cadastral plan "PCI" is a digital database (vector or scanned data) of land registry plans. It mainly contains land parcels and corresponding buildings if they exist. The topographic database 
BD TOPO ${ }^{\circledR}$ provides $3 \mathrm{D}$ reference information for all parties involved in town and country management. It contains a description of the landscape elements in the form of vectors filed according to a suitable theme. As an example, the theme we are working on is the buildings one.

We used both the IGN's topographic database and the cadastral plan data because the first one contains aggregated buildings footprints with heights (as attribute) and the second one contains the individual buildings footprints without heights. To have both the individual buildings footprints and their estimated elevation, a spatial data matching process was required (see Figure 2).

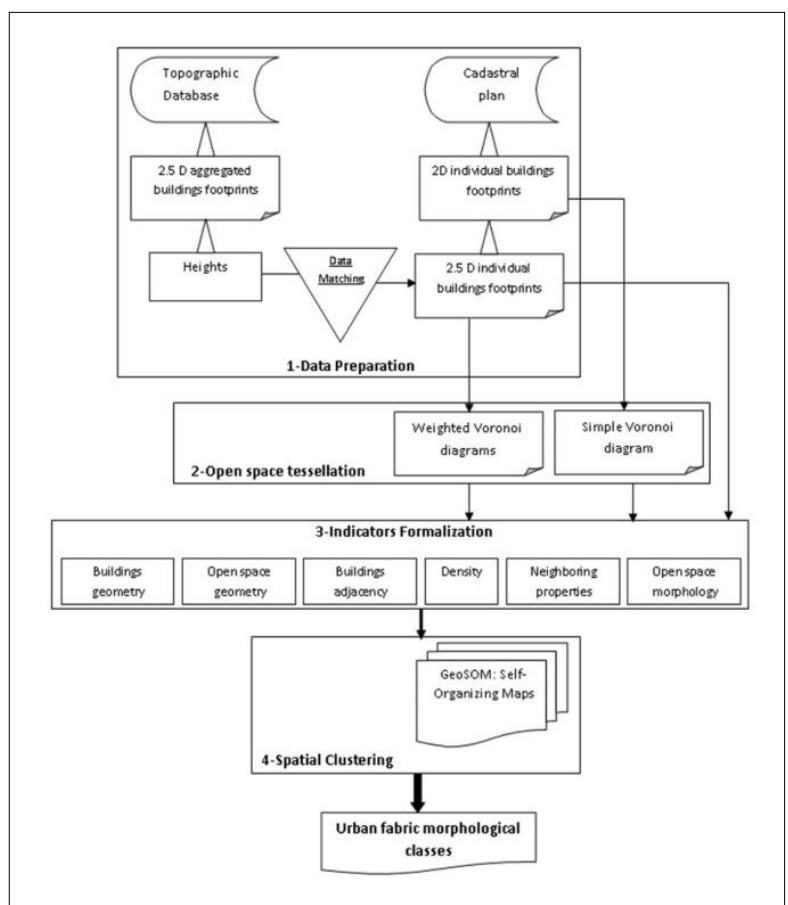

Fig. 1. Methodology pursued in this paper

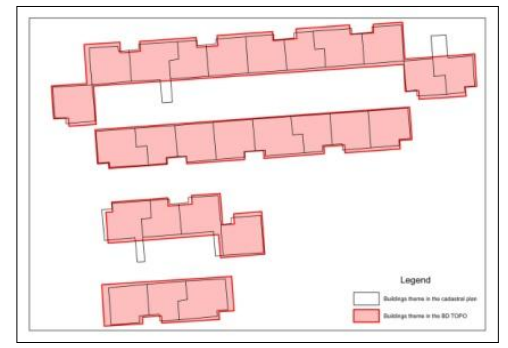

Fig. 2. Buildings theme in the topographic database and in the cadastral plan 


\section{Open space geometry}

Placing a new spatial object in a space introduces change in the configurational properties of this space. In the urban environment, every new building (as a new external morphological item introduced in its spatial context) induces in its immediate neighborhood some morphology's change. It impacts the status with respect to several configurational parameters and physical phenomena (visibility, lighting, air circulation, movement, etc.) around the concerned building (see Figure 3).

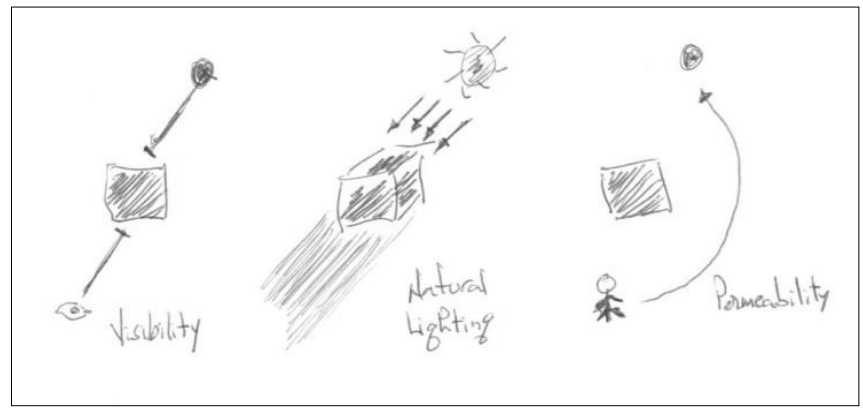

Fig. 3. A new building impacts visibility, lighting and permeability in its surrounding space

The introduction of each new building corresponds to a spatial integration of a sort of new attractor. By analogy, using a gravity model concept (the attraction that objects have for each other is set against the distance they are apart), this new building inserts a new item (cell) in the whole set of partitions, a new item which can be delineated by a sort of skeleton through the open space between its neighboring buildings.

This space tessellation is called a Voronoi diagram. Here, the tessellations represent some morphologic influence cells corresponding to individual buildings in the urban space. Let's assume that the contours of this space tessellation (a sort of urban open space skeleton) are the edges of a streets network. The same way, let's assume a pedestrian walk through the urban fabric using this (artificial) streets network; in each of the tessellation nodes, the walker will face substantial morphological changes. More precisely, these punctual locations correspond to most significant places in term of morphological changes (see Figure 4). 


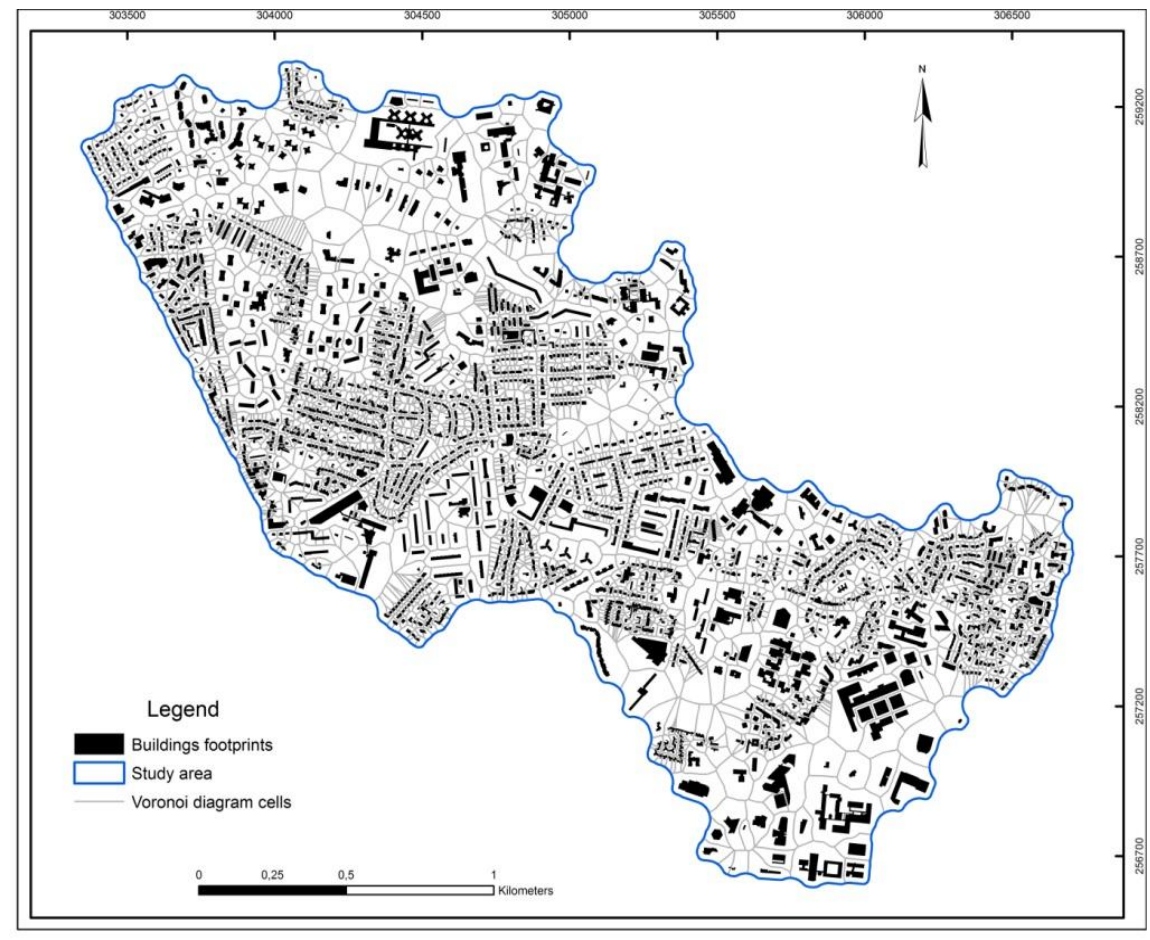

Fig. 4. Buildings footprints and corresponding Voronoi diagrams in the study area (northern districts of Nantes city, France)

Two variants of this tessellation can be defined: a simple and a weighted Voronoi diagram. The simple one is based on the Euclidean distance between neighboring buildings footprints (2D vision) whereas the second one is weighted by the volume of neighboring buildings (3D vision considering that the buildings mass may contribute more or less to the size of the morphology's cell influence). The results of this tessellation are three new spatial objects: the nodes (0D) in the Voronoi diagram intersections that are the locations of significant change on morphology, the skeleton edges (1D) that are sort of developed artificial streets and the Voronoi diagrams (2D) that are the morphological influence cells (they correspond, by analogy with ownership division, to a sort of morphologic plots). Furthermore, the intrinsic topology of these spatial objects allows defining a neighboring function that will be formalized and used later. We believe that these new spatial objects based on morphologic characteristics are more pertinent (for our morphological issues, at least) than the traditional ones based on administrative, ownership or other non-standardized partitions. 


\section{Urban morphological properties: formalizing indicators}

Our strategy in the choice of those properties is based on considering the urban space shaped by two simple spatial objects: buildings and surrounding open space. Each one has its own geometry and inner topology (the spatial relationships between spatial objects of the same nature: buildings for example). Furthermore, an external topology (the spatial relationships between the buildings and open spaces) should also be considered. We suppose that most relevant morphological properties come from these three elements: geometry, inner topology and external topology. So, we propose to model each of them into a very small set of indicators.

Table1 summarizes morphological properties and their corresponding indicators. This list contains some simple yet indispensable indicators especially those relative to architectural form (size and shape for example). Then, we propose a new formulation (or generalization) of a few others.

Our concern is to work only on buildings footprints and that the chosen indicators can be calculated on huge dataset and should be simple, easily interpretable and independent from urban contexts.

Table 1. Urban morphologic properties and corresponding indicators

\begin{tabular}{|c|c|c|c|c|}
\hline \multirow{3}{*}{$\begin{array}{l}\text { Urban objects } \\
\quad \text { involved } \\
\text { Morphological } \\
\text { Properties }\end{array}$} & \multicolumn{4}{|c|}{ Urban space } \\
\hline & \multirow[b]{2}{*}{ Buildings } & \multicolumn{2}{|c|}{ Open space } & \multirow[b]{2}{*}{ Buildings } \\
\hline & & $\begin{array}{l}\text { Voronoi di- } \\
\text { agrams }\end{array}$ & $\begin{array}{l}\text { Skele- } \\
\text { ton } \\
\text { nodes }\end{array}$ & \\
\hline & Size: L, 1, H, A, V & & & \\
\hline $\begin{array}{l}\text { Buildings } \\
\text { Geometry }\end{array}$ & $\begin{array}{l}\text { Shape: } \\
\text { minimum enclos- } \\
\text { ing area rectangle } \\
\text { compactness indi- } \\
\text { cator }\end{array}$ & & & \\
\hline $\begin{array}{l}\text { Open space } \\
\text { Geometry }\end{array}$ & & $\begin{array}{l}\text { Voronoi } \\
\text { cells area }\end{array}$ & & \\
\hline $\begin{array}{l}\text { Buildings } \\
\text { Adjacency }\end{array}$ & Party-walls ratio & & & \\
\hline Density & $\begin{array}{l}\text { Ground Spa } \\
\text { Floor Spac }\end{array}$ & $\frac{\text { Index }}{\text { Index }}$ & & \\
\hline Neighboring & & & $\begin{array}{l}\text { Mean bu } \\
\text { tance }\end{array}$ & ings dis- \\
\hline & & & Gene & ized W/H \\
\hline $\begin{array}{l}\text { Open space mor- } \\
\text { phology } \\
\text { (spatial openness) }\end{array}$ & $\begin{array}{l}\text { Sky openness: } \\
\text { sky view factor }\end{array}$ & & $\begin{array}{l}\text { Grou } \\
\text { Isovist a } \\
\text { Volume } \\
\text { building }\end{array}$ & $\begin{array}{l}\text { openness: } \\
\text { / Disk area } \\
\text { visible } \\
\text { Isovist area }\end{array}$ \\
\hline
\end{tabular}




\section{Buildings geometry}

Obviously, the architectural form is required in urban form characterization (see Figure 5). From buildings footprints data, the simple architectural form can be evaluated by its size (template) and its shape measurements. The size measurements used here are: L: length, l: width, $\mathrm{H}$ : height, A: area, and V: volume. Shape evaluation is based first on the comparison between the area of the concerned building with the area of the minimum enclosing area rectangle as a sort of architecture complexity measure and second on the compactness indicator $(\mathrm{CI})$ of the building footprint:

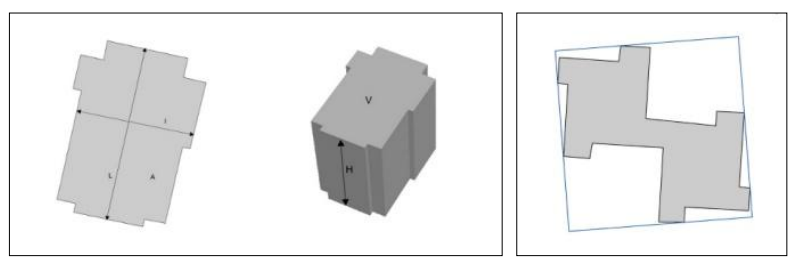

Fig. 5. Some simple building's descriptors: length, width, area, height, volume and minimum enclosing area rectangle of a building footprint

\section{Open space geometry}

Urban environmental conditions strongly depend on urban space morphology. As an example, the amount of air (ventilation) and natural lighting of buildings depend on the urban space openness and consequently on surrounding open space geometry (see Figure 6). We assume that a very simple way to measure it can be the area of the weighted Voronoi diagrams introduced before and considered here as some vital space all around each building (required to supply air and light). By analogy, this is just like the plot size in some administrative morphologic based division.

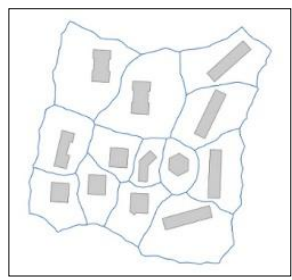

Fig. 6. Open space partition using a weighted Voronoi diagrams 


\section{Buildings adjacency}

The party-walls of a building are sort of ghost (dead) façades. They don't face a buffer of urban open spaces that can facilitate the circulation of air and light. Therefore, the ratio of these walls in comparison to the entire façades is morphologically very important (possible distinction between detached houses, semi-detached houses, etc). It is calculated here as the ratio between the party-walls length and the building footprint's perimeter (see Figure 7). However, it can be extended in 3D ratio between the surface of shared façades and the entire building's surface of façades.

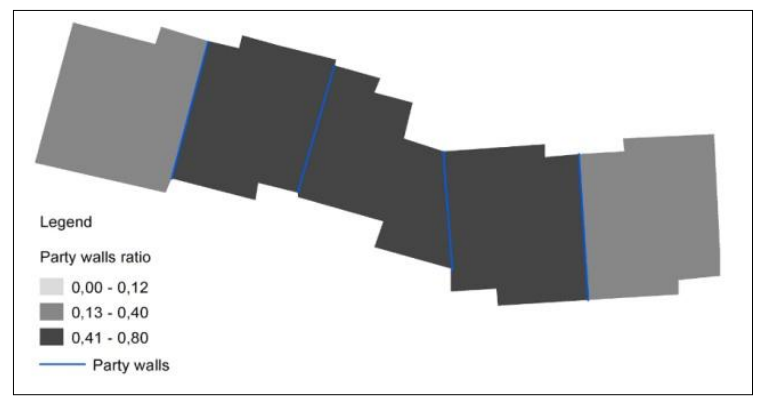

Fig. 7. Party walls ratio as a buildings adjacency characterization

\section{Density}

Density is perhaps the most used indicator to characterize urban development. The open space partition based on buildings geometry (presented before) allows measuring some density indicators considering a reference surface based on urban space morphology and not on land ownership as traditionally done (considering the Voronoi diagrams as some artificial urban plots). This method solves the well-known reference area issue (such as to use the plot, the urban block, the district, or the town itself) to measure density in urban areas. Also, with such a space partition, there is no need to have plots data. This is generally hard to produce and rarely available for privacy (ownership) considerations.

The first indicator that we decide to transpose to this new way of urban space partition is the ground space index (GSI). In our renewed approach, the GSI corresponds to the ratio between the building's footprint area and the corresponding Voronoi diagram's cell area. The second one is the floor space index (FSI), the ratio between the building volume and the corresponding Voronoi diagram's cell area (see Figure 8). Even if the GSI and FSI are commonly used in urban studies, their calculation over artificial morphological plots (instead of administrative plots) gives them more relevance for urban morphology characterization purposes. 


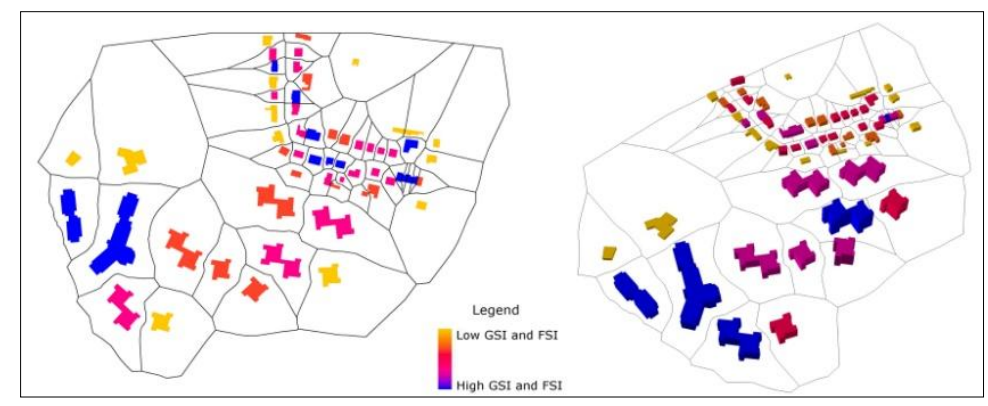

Fig. 8. Buildings density indicators: GSI (left) and FSI (right)

\section{Neighboring properties}

The Voronoi diagram partition topology allows defining a neighboring function based on the shared borders (in the sense of a spatial intersection) of this Voronoi diagrams. This function is defined by a spatial topologic relationship as following:

Let's $\mathrm{V}=\left\{\mathrm{V}_{1}, \mathrm{~V}_{2}, \ldots, \mathrm{V}_{\mathrm{i}}, \ldots, \mathrm{V}_{\mathrm{n}}\right\}$ the set of Voronoi diagram cells and $\mathrm{N}=\left\{\mathrm{N}_{1}, \mathrm{~N}_{2}, \ldots, \mathrm{N}_{\mathrm{i}}, \ldots, \mathrm{N}_{\mathrm{n}}\right\}$ the set of neighbors.

$$
\mathrm{N}_{\mathrm{i}}=\left\{\mathrm{V}_{\mathrm{j}}, \mathrm{V}_{\mathrm{k}}, \ldots, \mathrm{V}_{\mathrm{m}}\right\} \text { if } \mathrm{V}_{\mathrm{i}} \cap\left\{\mathrm{V}_{\mathrm{j}}, \mathrm{V}_{\mathrm{k}}, \ldots, \mathrm{V}_{\mathrm{m}}\right\} \neq \varnothing
$$

Based on this function, a first neighboring characterization is produced for every building by the mean distance of the given building to its nearest neighbors. The edges of the Voronoi diagram draw a sort of skeleton of the urban open space. As mentioned above, this skeleton is considered here as a highly developed streets network (like the one defined in the Space Syntax approach). Therefore, every edge of the skeleton network can be considered by analogy as an artificial street. Using this skeleton and the neighboring function, we propose a generalization of the building to street proportion measure (street width/buildings height) traditionally used in urban studies and originally designed for urban closed environments [Landsberg, 1981].

This indicator is calculated for the nodes of the skeleton network in the Voronoi diagrams intersections corresponding to the locations of urban morphological change. The neighboring buildings involved in this calculation are those corresponding to the Voronoi diagrams involved in each intersection (node). The street width is therefore replaced by the distance between the node and the neighboring buildings over the open space. Then, this generalized ratio $\mathrm{W} / \mathrm{H}$ (W: distance between the node and the neighboring building, $\mathrm{H}$ : height of the neighboring building) calculated for every morphologic node is averaged over all the nodes of the Voronoi diagram corresponding to the building of concern (see Figure 9). 
We can notice that the previous neighboring indicator (mean distance to the nearest neighbors) is a kind of simplification using a $2 \mathrm{D}$ conception of this $3 \mathrm{D}$ generalized ratio.

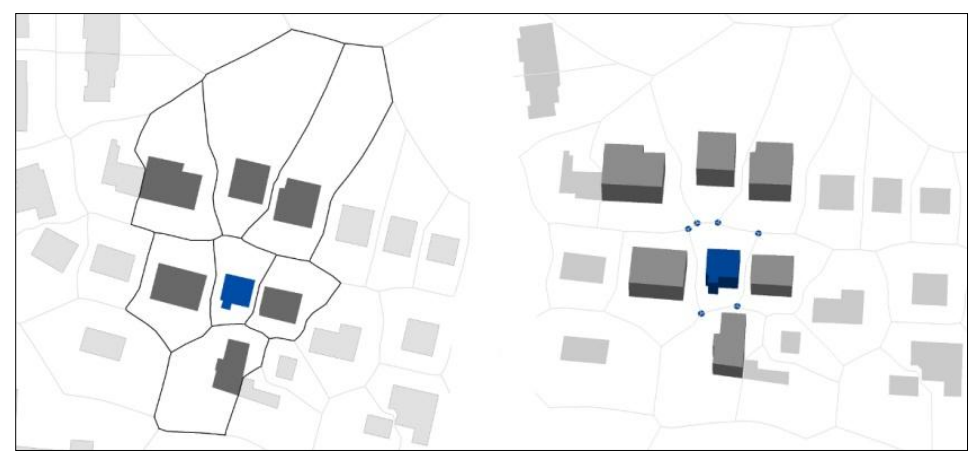

Fig. 9. Mean distance to the nearest neighbors (left) and generalized W/H ratio (right) for a given building

\section{Open space morphology}

The most important property of the urban space morphology seems to be the spatial openness [Fisher-Gewirtzman et al., 2003] (versus promiscuity). So, we propose to characterize the open space morphology by an evaluation of the spatial openness in the locations of morphology's change. This can be measured using two components: sky openness and ground openness.

Sky openness: The sky view factor [Souza et al., 2003] is commonly used to measure sky openness. It is the proportion of visible sky in comparison with the sky masked by other buildings in the concerned location (see Figure 10). This value is very important for natural lighting, solar radiation and even for the pedestrian comfort conditions [Krüger et al., 2011]. Just as we did with the indicators calculated in the locations of morphology change, the sky view factor is averaged over all the locations belonging to the Voronoi diagram corresponding to the buildings of interest.

Ground openness: Human perception and experience are intensively used to assess the quality of urban environments. The ground openness expresses some users (occupiers) spatial perception of the urban environment regarding the intensity of occupation of space by built-up areas. We propose an evaluation of the degree of ground openness based on partial isovists (urban viewshed) [Benedict, 1979] of 200m radius computed in the locations of urban morphology change. This is the ratio between the isovist area in the location of concern and the area of a whole isovist (400m di- 
ameter disk). This 2D indicator can be fulfilled by a 3D one considering the ratio between the volume of visible buildings and the isovist area (see Figure 11) to express some degree of enclosure [Stamps, 2005]. The chosen radius $(200 \mathrm{~m})$ is in some way an arbitrary threshold assuming that pedestrians will not be impacted by the presence of a building over this distance

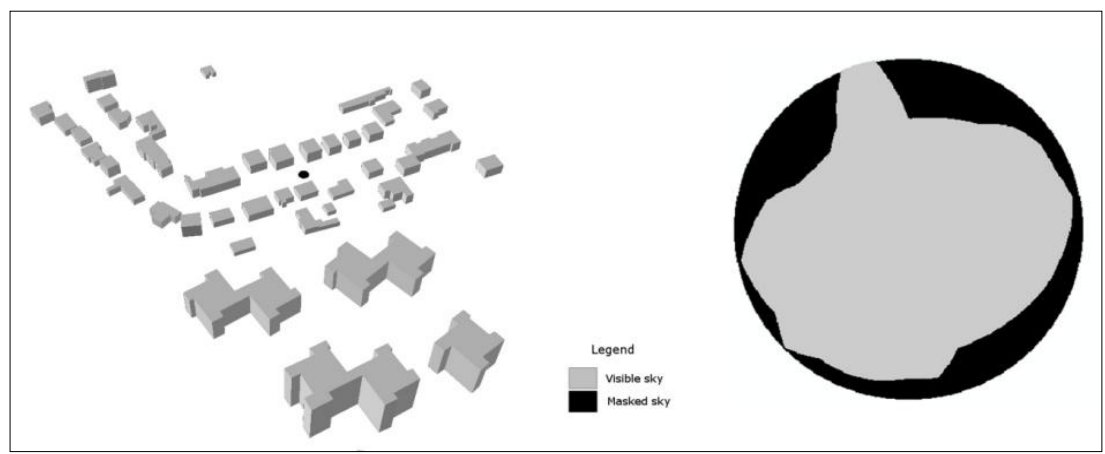

Fig. 10. Sky shape in a given urban location

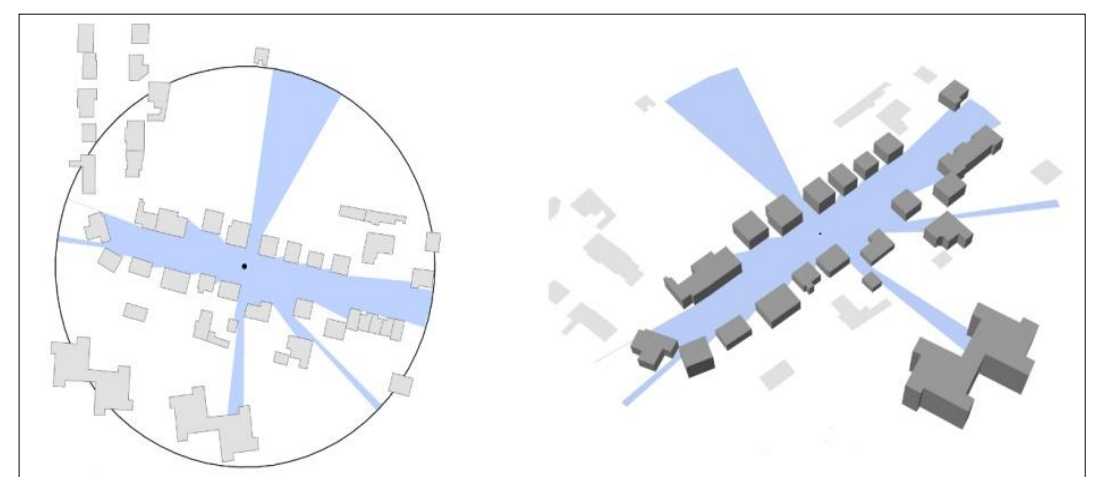

.Fig. 11. 2D (right) and 3D (left) ground openness measures

At this stage, each building (and the corresponding Voronoi diagram) is characterized by several morphological indicators. The next step is to perform some clustering process on these data.

\section{Self-organizing maps}

The complexity of urban environments arises out of the variety of its constituent elements: buildings, streets, open space, etc. As seen before, each element has its own properties and each property can be measured using 
several indicators. Furthermore, the spatial heterogeneity of architecture and urban form is very frequent in the cities. This finally creates highly dimensional datasets with some spatial constraints in the urban fabrics characterization process, hence the need for a classification approach.

The spatial clustering analysis required for this kind of task is an unsupervised classification aiming at grouping a set of spatial objects into meaningful subclasses maximizing inter-class similarity and minimizing intraclass similarity. Among spatial clustering techniques, self-organizing maps (SOM) are an artificial intelligence approach and a neural network method based on unsupervised learning and it is self-organizing [Kohonen, 2001].

Self organizing maps work by mapping a high-dimensional data into 1, 2 or 3 dimensional feature maps (see Figure 12).
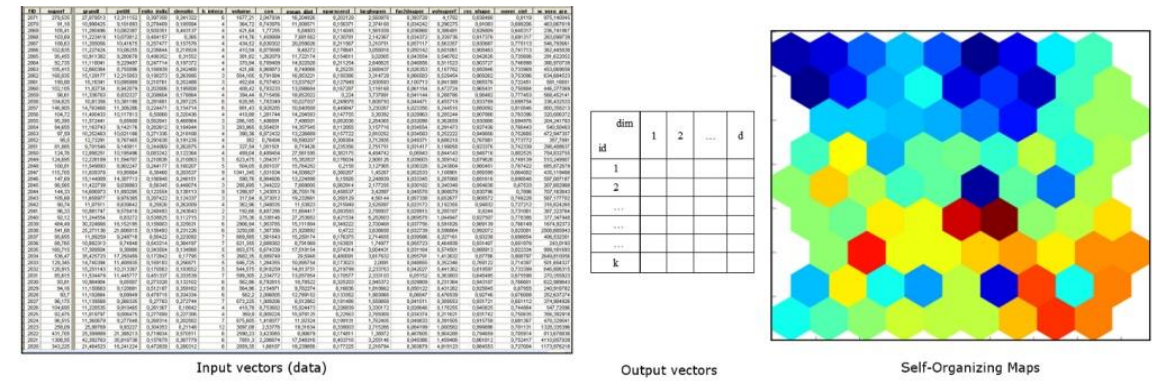

Fig. 12. Running principle of the self-Organizing maps

The geo-referenced data SOM (Geo-SOM) [Henriques et al., 2009] used here is a variation of original SOM that considers the spatial nature of data. For more details about SOM and Geo-SOM, refer to [Kohonen, 2001] and [Bação et al., 2004].

We focus on the northern urban fabrics of Nantes city (see Figure 4). This zone is about $5 \mathrm{~km}^{2}$. It was chosen because of the variety of architecture and urban form it encloses: residential areas (high-rise blocks: towers and large scale blocks, low-rise houses), services and equipment areas with some particular architecture: campus university, penitentiary building, schools, etc. Our input data consists of the set of Voronoi diagrams corresponding to the 2872 buildings in the entire study area described by the sixteen previously developed morphological indicators. This is a $2872 * 16$ matrix besides the geographical coordinates of the items. We used the GeoSOM suite to process input data and used the output called U-matrix [Henriques et al., 2009] to define the twelve spatial clusters on these data. 


\section{Results}

Figure 13 presents the results of a global clustering process using all morphological indicators. This is a delineation of urban sub-areas exhibiting similar morphological characteristics. As we did in the morphological indicators formalization, we will discuss both, the contribution of the architectural or geometrical properties and the topological ones (internal and external) in the classification process. Even if some morphologic properties measurements taken individually can yet be used to do some rough urban fabrics characterization and to distinguish some rough urban fabrics types from others, we won't discuss them individually nor develop the results of all of them.

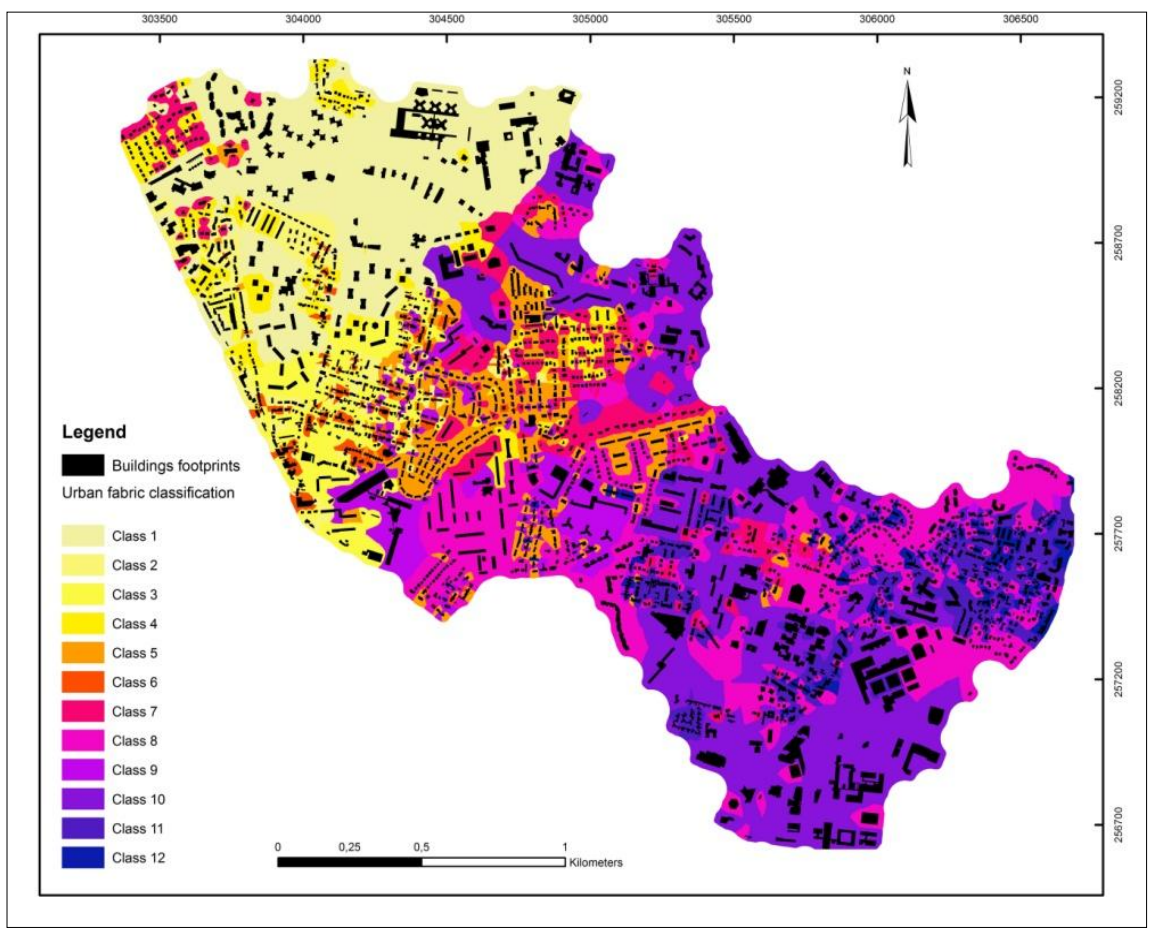

Fig. 13. Classification of urban fabrics in the study area

\section{Geometry contribution}

Obviously, houses and other low-rise buildings (generally having simple architecture, i.e. small size and simple shape) are distinguished from more complex architectural buildings such as university campuses, penitentiary buildings, schools, and so on (generally big size and complex shape) as 
well as from high-rise buildings such as towers and large scale blocks (generally big size and simple shape). Also, some isolated buildings with a different architecture from the neighboring buildings are highlighted (this usually happens in the high-rise buildings areas where few low-rise (small) buildings are used for services (shops, public offices, etc.). Also, it is possible to distinguish small size individual housing (generally aggregated) from modern low-rise housing in the suburban areas.

\section{Topology contribution}

Figure 14 presents the results of a partial spatial clustering process based on four indicators (from the sixteen previously developed and corresponding to neighboring, sky and ground openness properties). These are calculated on the skeleton nodes and represent the topological properties. The classification resulting from this clustering process highlights most of the common urban fabrics types in the study area and used for example in the master plan of urban regulation "Plan local d'urbanisme: PLU". Furthermore, this classification gives much more details about the urban fabrics morphology than the "PLU" zoning. The open space properties allow distinguishing several urban areas going from axial morphologies where streets structure the spatial layout of the urban fabric to the very open (diffuse) morphologies where the spatial layout is no longer structured by streets and the buildings are no longer located alongside streets but scattered throughout space.

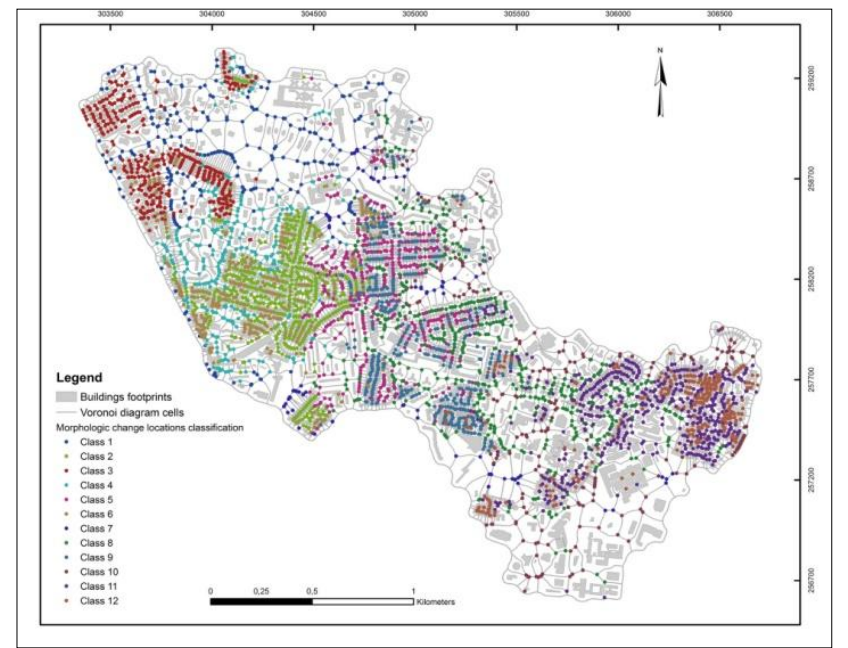

Fig. 14. Classification of the morphological change locations in the study area 
The use of the morphological properties with respect to the open space in combination with the geometric ones allows highlighting some urban structures difficult to assess by visual inspection and generally lacking in traditional descriptive characterizations (see Figure 15). This is the case of some buildings groups that are distinguished from their neighbors thanks to their different neighborhood characteristics even if all of these buildings exhibit similar architectural form. These different neighborhood characteristics can be spatial openness measurements or different buildings adjacencies or different $\mathrm{W} / \mathrm{H}$ ratio measures. For example, this is the case of the buildings groups highlighted for overlooking green areas (vast open spaces) in some direction or aggregated in some particular way.

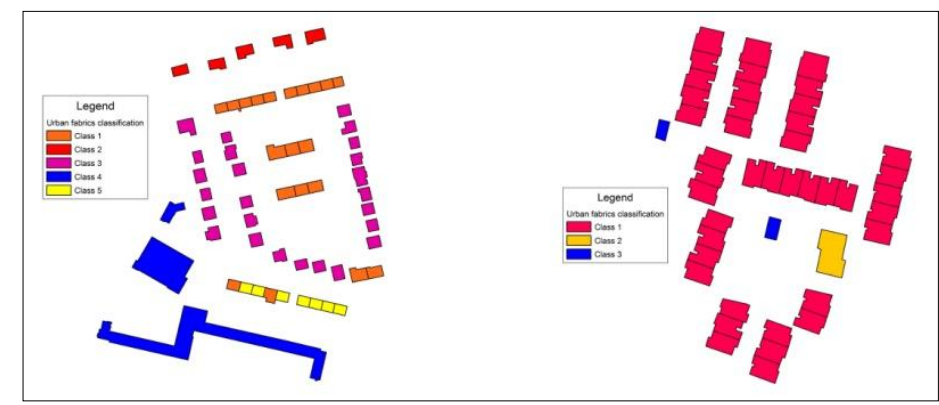

Fig. 15. Some buildings structures highlighted in the urban fabrics classification

\section{Conclusion}

The analysis developed in this work is based on a buildings footprints layer that is the simplest spatial model (the easier to produce) for the urban environment representation. We formalized some concepts of urban morphology on a very few set of morphologic properties and translated them into few indicators that can be easily computed in a GIS framework. This produced a highly dimensional data for every footprint characterizing both the building and its associated open space. Then, we reduced and classified this data using self-organizing maps. The results show that this analytical method is powerful, robust and more complete than traditional descriptive classifications generally lacking open space properties. It is possible in very heterogeneous environments that the classification produces a very high number of spatial structures. In this case, there is a trade-off to take into account between a high resolution (high level of morphologic details) and easy interpretability (formal description) of the results of such approach. This will of course depend on the purpose to which the characteri- 
zation (classification) is to be put (application). However, when the typology can be used as it is (some urban modeling and simulation studies), this approach can be very useful. The characterization developed here can easily be extended (enriched) introducing some intra-urban land cover (and land use) data in the morphological properties and especially associated with the urban open space geometry. This can be for example the proportion of every morphological cell (Voronoi diagram) occupied by vegetation since vegetation is becoming a very important issue in recent urban climate studies.

\section{References}

Bação F., Lobo V., Painho M., 2005, "The self-organizing map, the Geo- SOM, and relevant variants for geosciences", Computers and Geosciences, 31(2), 155-163.

Benedict M L., 1979, "To take hold of space: isovists and isovist fields", Environment and Planning B: Planning and Design, 6, 47-65.

Berghauser-Pont I., Haupt P., 2007, "The Spacemate: density and the typomorphology of the urban fabric", Urbanism laboratory for cities and regions: progress of research issues in urbanism.

Boffet A., Serra S.R., 2001, "Identification of spatial structures within urban blocks for town characterization", 20th International Cartographic Conference.

Couclelis H., 1992, "People Manipulate Objects (but Cultivate Fields): Beyond the RasterVector Debate in GIS". In Frank, A. U., Campari, I., and Formentini, U., editors, Theories and Methods of Spatio-Temporal Reasoning in Geographic Space, International Conference GIS - From Space to Territory: Theories and Methods of Spatio-Temporal Reasoning, Lecture Notes in Computer Science, pages 65-77, Pisa, Italy. Springer.

Fisher-Gewirtzman D., Wagner I. A., 2003, "Spatial openness as a practical metric for evaluating built-up environments", Environment and Planning B: Planning and Design, 30(1), 37-49.

Henriques R., Bação F., Lobo V., 2009, "GeoSOM Suite: A Tool for Spatial Clustering", Computational Science and Its Applications: ICCSA.

Hillier B., 1987, "La morphologie de l'espace urbain : l'évolution de l'approche syntaxique", Architecture et Comportement, 3(3), 205-216.

Kohonen T., 2001, "Self-Organizing maps", third ed, Springer, Berlin-Heidelberg 501 pp.

Krüger E.L., Minella F.O., Rasia F., 2011, "Impact of urban geometry on outdoor thermal comfort and air quality from field measurements in Curitiba, Brazil", Building and Environment, 46, 621-634.

Landsberg H.E., 1981, "The urban climate", Academic Press (New York), 275p.

Puissant A. Skupinski G., Lachiche N., Braud A., Perret J., 2010, "Classification des tissus urbains à partir de données vectorielles - application à Strasbourg", Spatial Analysis and GEOmatics: SAGEO'10, 198-211.

Souza R., Rodrigues D., Mendes J., 2003, "Sky view factors estimation using a 3D-GIS extension", Eighth International IBPSA Conference.

Stamps A. E., 2005, "Isovists, enclosure, and permeability theory", Environment and Planning B: Planning and Design, 32(5), 735-762.

Thomas I., Frankhauser P., Keersmaecker M.L., 2007, "Fractal dimension versus density of built-up surfaces in the periphery of Brussels", Papers in Regional Science, 2(06), 287308 . 